\title{
Predicting Correctional Officer Job Performance Using the Critical Hire-Screen and Personality Assessment Inventory: An Analysis of Incremental Validity
}

\author{
Anthony Tatman \\ Critical Hire \\ PO Box 813, 500 Hickman Rd., Waukee, Iowa 50263-7713 \\ E-mail: tonytatman@criticalhire.com
}

Received: Aug. 15, 2019 Accepted: Dec. 20, 2019 Online published: Jan. 2, 2020

doi:10.5296/ijhrs.v10i1.16170 URL: https://doi.org/10.5296/ijhrs.v10i1.16170

\begin{abstract}
This article measured the degree to which the Critical Hire-Screen (CH-S), a pre-employment test of integrity, and Personality Assessment Inventory (PAI), a test of psychopathology, correlated with and predicted supervisor ratings of correctional officer job performance. Results revealed that the $\mathrm{CH}-\mathrm{S}$ provided the strongest correlation with, and prediction of, job performance. Although PAI subscales contributed to the prediction model, relatively few subscales were ultimately selected, resulting in the $\mathrm{CH}-\mathrm{S}$ explaining the majority of the variance. Implications for correctional agencies and pre-employment evaluators are discussed, and recommendations for the practical application of these results to pre-employment testing process are provided.
\end{abstract}

Keywords: Integrity testing, preemployment testing, Incremental validity, Critical Hire-Screen, Personality Assessment Inventory

\section{Introduction}

Counterproductive work behaviors (CWBs), poor job performance and deficiencies in integrity are problematic for any organization but may be especially concerning for correctional agencies where its officers are entrusted to uphold the law, protect the public, and serve as agents of change for their clients. With this expectation and responsibility, correctional officers have been given considerable power and authority, and in some cases are certified to carry firearms and enabled with full arrest authority (Roscoe, Duffee, Rivera, \& Smith, 2007; Small \& Torres, 2001). As a result, correctional departments have begun implementing pre-employment integrity and psychological testing as part of their hiring 
process in order to help evaluate the degree to which these applicants have the level of integrity and emotional stability needed for high-risk, high-stress careers in corrections (Herrmann \& Bedwell, 2014; Shusman \& Inwald, 1991; Tatman \& Huss, 2019b; Tatman, Kreamer, \& Dix, 2014).

Pre-employment integrity tests have been identified as the most widely used type of assessment tool for predicting counterproductive work behaviors among job applicants and employees (Fine, Horowitz, Weigler, \& Basis, 2010). This popularity and widespread use has occurred, in large part, from the extensive empirical evidence supporting integrity test's reliability and validity in predicting job performance and counterproductive work behaviors such as theft, tardiness, property damage, rule-breaking, violence and absenteeism (Berry, Sackett \& Wiemann, 2007; Fine, 2013; Fine et al., 2010; Jones, Cunningham, \& Dages, 2010; Marcus, Ashton, \& Lee, 2013; Nicol \& Paunonen, 2002; Ones, Viswesvaran, \& Schmidt, 1993; Ones, Viswesvaran, \& Schmidt, 2003; Schmidt \& Hunter, 1998; Schmidt, Oh, Shaffer, 2016; Wanek, 1999). The Critical Hire-Screen (CH-S; Tatman, 2019a) is a pre-employment integrity assessment that has been developed exclusively for law enforcement and correctional applicants. The $\mathrm{CH}-\mathrm{S}$ measures five unique integrity factors, social desirability, and has been shown to have strong reliability, concurrent validity, and divergent validity (Tatman \& Huss, 2019a; Tatman \& Huss, 2019b). The CH-S has also been found to have strong criterion validity, producing relative risk ratios ranging from $3.68(p=.0004)$ to 5.80 $(p<.0001)$ when predicting supervisor ratings of job performance (Tatman, 2019b).

Similar to pre-offer integrity tests, the use of post-conditional offer psychological tests have also become commonplace in law enforcement hiring process. Although not as widespread as in hiring processes for police officer candidates, many corrections agencies have begun to use psychological testing as part of their hiring process for correctional officers (Herrmann \& Bedwell, 2014; Shusman \& Inwald, 1991; Tatman et. al., 2014). The Personality Assessment Inventory (PAI; Morey, 2007) is a well-known, researched and utilized measure of psychopathology frequently incorporated into pre-employment, psychological evaluations for law enforcement and correctional officer applicants (Weiss, 2010; Weiss \& Weiss, 2010). The PAI has been found to have adequate accuracy in predicting supervisor ratings of police officer job performance, insubordination, integrity problems, citizen complaints, termination for cause, neglect of duty, and abuse of disability status (DeCoster-Martin, Weiss, Davis, \& Rostow, 2004; Lowmaster \& Morey, 2012; Weiss, Hitchcock, Weiss, Rostow, \& Davis, 2008; Weiss, Rostow, Davis, Decoster-Martin, 2004; Weiss, Zehner, Davis, Rostow, \& Decoster-Martin, 2005). Unfortunately, although there is sufficient research supporting the use of the PAI in pre-employment evaluations for police officers, the literature is scarce in regard to its use with correctional officers.

\subsection{Incremental Validity in Pre-Employment Testing}

A variety of instruments and methods have been used to help hiring agencies identify counter productive work behaviors, predict future performance problems, and enhance the hiring process. These instruments and methods have included things like integrity tests, structured interviews, work samples, job knowledge tests, and even handwriting analysis. However, not 
all these methods have been shown to work or provide incremental validity to the hiring process (Schmidt \& Hunter, 1998). Incremental validity is the degree to which an added instrument or method will increase the predictive accuracy beyond that provided by the existing process (Sackett \& Lievens, 2008). If a method or measure does not contribute incremental validity to an existing process it could have substantial financial and resource implications for the hiring agency. For example, occupational interest inventories can be expensive and time consuming to administer and interpret but have been found to have little impact on the overall incremental validity or predictive accuracy for future job performance (Schmidt \& Hunter). Therefore, adding an occupational interest test to an existing hiring process may do nothing for the process but cost the employer time and money. The use of integrity tests, however, have been found to add significantly to the hiring process. Schmidt and Hunter conducted one of the largest reviews of the pre-employment literature to date and concluded that general mental ability (GMA) was the single best predictor of job performance and on-the-job learning. Combining integrity tests with tests of GMA, however, improved the predictive accuracy by $27 \%$, adding significant incremental validity above and beyond what was provided solely by GMA.

Despite the widespread use of the PAI in pre-employment evaluations for correctional officer applicants (Roberts, Thompson, \& Johnson, 1999; Weiss, 2010; Weiss \& Weiss, 2010) the relationship between the PAI and integrity test scores, when used with correctional officer applicants, has not been investigated. Therefore, this study was conducted to measure the degree to which $\mathrm{CH}-\mathrm{S}$ and PAI scale scores (independent variables) are associated with supervisor ratings of correctional officer job performance (dependent variable), and the degree to which the $\mathrm{CH}-\mathrm{S}$ and PAI provide incremental validity to the prediction of supervisor ratings. Specifically, based on the aforementioned literature, this author hypothesized that: 1) $\mathrm{CH}-\mathrm{S}$ and PAI scores would significantly correlate with supervisor ratings of job performance, 2) $\mathrm{CH}-\mathrm{S}$ and PAI scores would predict supervisor ratings of job performance, 3) $\mathrm{CH}-\mathrm{S}$ would provide the strongest contribution to the prediction model, and 4) that PAI scores would provide incremental validity to $\mathrm{CH}-\mathrm{S}$ scores when predicting supervisor ratings of correctional officer job performance.

\section{Methods}

\subsection{Participants}

Archival data was obtained from participants pursuing employment as correctional officers from various correctional agencies in the State of Iowa. As part of a comprehensive, pre-employment testing process, applicants for probation officer, parole officer, residential officer, and correctional treatment provider positions (i.e., correctional officers) from multiple community-based corrections agencies across Iowa completed the $\mathrm{CH}-\mathrm{S}$ during the pre-conditional offer phase of the hiring process. This same sample also completed the PAI during the post-conditional offer phase of the hiring process. Selection for inclusion in this study also required that participants were employed with the hiring agency for at least 1 year at the time of this study to allow ample time for supervisory evaluations. Ninety-seven employees (58 males and 39 females) were identified from this archival data as meeting this 
criterion. The sample had an average age of 36.67 ( $\mathrm{SD}=9.20)$, which ranged from 20 to 61 years of age. Racial composition consisted of 79 Caucasian, 11 African American, 5 Hispanic, and 2 Asian participants.

\subsection{Measures}

The Critical Hire-Screen (CH-S; Tatman, 2019a) is an overt integrity assessment that can be used at a pre- or post-conditional offer phase in the hiring process, and has norms developed specifically for correctional officer applicants. The $\mathrm{CH}-\mathrm{S}$ measures five factors of integrity: Substances (i.e., use or selling of drugs in the workplace, and/or use of alcohol in the workplace), Theft (i.e., theft in the workplace), Authority (i.e., disparaging or conflictual opinions about management and supervisors), Rules \& Deception (i.e., rule breaking, manipulating others, and deceptive behaviors), and Personal Responsibility (i.e., the degree to which an applicant places blame on victims for crimes committed against them). When an integrity factor reaches an elevated level (i.e., 1.5 SD) it is identified as being a Critical Factor. When an applicant answers an item in a way that significantly deviates from the normative population (i.e., an answer provided by $20 \%$ or less of the normal sample) it is identified as being a Critical Item. Both Critical Factors and Critical Items have been found to be significantly correlated with, and predictors of, supervisor ratings of job performance for correctional officers (Tatman, 2019b). Specifically, Tatman (2019b) found that CH-S scales significantly correlated with supervisor ratings of job performance for correctional officers $\left(r_{p b}\right.$ ranging from .24 to .27 ). Relative risk ratios also found that when correctional applicants generated 3 or more Critical Items (i.e., item responses that significantly deviated from the normative sample) their risk for being identified as a "mis-hire" was 5.6 times greater than compared to examinees with 2 or fewer Critical Items (Tatman, 2019b). Tatman (2019a) also reports a ROC area of $.89(95 \%$ C.I. $=.72$ to 1.0$)$ when measuring the degree to which Critical Items predicted supervisor ratings of job performance. Tatman (2019b) also found that Critical Factors were predictive of job performance ratings. Using a cut score of 2 or more Critical Factors resulted in a ratio score of $3.68(p=.0004)$ when predicting supervisors ratings of job performance. This finding suggests that individuals who generate 2 or more Critical Factors are over 3 times more likely to be classified as mis-hires than employees generating 0 or 1 Critical Factors. In addition to its criterion validity, the $\mathrm{CH}-\mathrm{S}$ has been found to have adequate content and concurrent validity, as well as test-retest reliability and internal consistency (Tatman \& Huss, 2019a; Tatman \& Huss, 2019b). The CH-S also incorporates an impression management scale (IMS), which has been found to have strong reliability, concurrent validity in measuring social desirability, and criterion validity for predicting poor employee ratings by supervisors (Tatman \& Huss, 2019b; Tatman, 2019b). Therefore, based on this existing literature $\mathrm{CH}-\mathrm{S}$ Critical Items, Critical Factors, and IMS were included as independent variables in this study.

The Personality Assessment Inventory (PAI; Morey, 2007) was also used in this study and is a measure of adult personality and psychopathology. For purposes of this study, only the 30 clinical subscales and the Aggression treatment scale were analyzed (Table 1). Each PAI clinical scale contains multiple subscales that are combined to generate the clinical scale score. Therefore, subscales were chosen as independent variables over clinical scales for this 
study, due to the greater specificity and unique psychological construct provided from each subscale compared to their aggregate clinical scale. The Aggression treatment scale was included in this analysis based on its face and content validity for measuring a psychological trait commensurate with problematic workplace behaviors.

\subsection{Procedures}

Supervisors for each participant who completed the $\mathrm{CH}-\mathrm{S}$ were asked to rate their respective employee(s) job performance on a Likert scale of 1 (Low Performer; $\mathrm{N}=6$ ), 2 (Below Average Performer; $\mathrm{N}=9$ ), 3 (Average Performer; $\mathrm{N}=59$ ), 4 (Above Average Performer; $\mathrm{N}$ $=19$ ), and 5 (High Performer; $N=4$ ). Supervisors rated correctional officer employee performance without reference to, or knowledge of, the employee's CH-S or PAI scores.

Pearson correlations were used to measure the degree of linear relationship between $\mathrm{CH}-\mathrm{S}$ scales and PAI subscales with supervisor ratings of job performance. $\mathrm{CH}-\mathrm{S}$ scales and PAI subscales producing significant Pearson correlation coefficients were then entered into a stepwise multiple regression to measure the degree to which the $\mathrm{CH}-\mathrm{S}$ and PAI scale scores predict supervisor ratings of job performance. Variables identified as significantly predicting job performance were then further analyzed using relative risk ratios, sensitivity, specificity, positive predictive values (PPV), and negative predictive values (NPV) in order to identify cut scores which could aid practical application of these findings. PPV and NPV measure the degree to which a tool's prediction of risk agree with known, observed risk (i.e., calibration). PPV measures high-risk accuracy and answers the question "If a test is positive for X, what is the likelihood the person actually has X?" PPV, for this study, is the probability that an individual with an elevated score on the $\mathrm{CH}-\mathrm{S}$ or PAI will receive below average supervisor ratings of job performance (i.e., poor performance). NPV measures low risk accuracy and answers the question "If a test is negative for $\mathrm{X}$, what is the likelihood that the person does not have X?" NPV, for this study, is the probability that the individual without an elevated score on the $\mathrm{CH}-\mathrm{S}$ or PAI has average or above average supervisor ratings of job performance (i.e., good performance). Sensitivity and specificity metrics, on the other hand, measure the degree to which an assessment can differentiate between two outcomes (i.e., discrimination). A tool's sensitivity is the degree to which the tool can correctly identify the issue or concern at hand. In this study sensitivity measures the degree to which the $\mathrm{CH}-\mathrm{S}$ and PAI can correctly identify poor job performance from the sample population. A tool's specificity is the degree to which a tool can correctly identify the absence of the issue or concern in question. In this study specificity measures the degree to which the $\mathrm{CH}-\mathrm{S}$ and PAI can correctly identify good job performance out of the sample population. Global accuracy (calculated by true positive + true negative/sample size) was also conducted to identify the degree to which the CH-S and PAI can correctly classify individuals rated as having either poor or good job performance. Risk ratios, also known as relative risk ratios, were also calculated to identify the probability at which $\mathrm{CH}-\mathrm{S}$ scales and PAI subscales can predict poor performance.

\section{Results}

The analyses began by conducting Pearson correlations between the $\mathrm{CH}-\mathrm{S}$ scales and PAI subscales and supervisor ratings of job performance. Results revealed significant, negative 
correlations between all three $\mathrm{CH}-\mathrm{S}$ scales and supervisor ratings (Table 1). This finding would suggest that as $\mathrm{CH}-\mathrm{S}$ scores increased ratings of job performance significantly decreased. Results also revealed significant, negative correlations between supervisor ratings and PAR-Persecution, PAR-Resentment, BOR-Self-Harm, ANT-Egocentricity, and AGG-Aggressive Attitude subscales of the PAI (Table 1). This negative relationship would suggest that as these PAI subscale scores increased supervisor ratings of job performance decreased. The PAI ARD-Obsessive-Compulsive subscale was also found to have a significant relationship with ratings of job performance. However, this relationship was positive, suggesting that as ARD-Obsessive-Compulsive decreased supervisor ratings also decreased. Inter-scale correlation coefficients between the CH-S scales and the above PAI subscales (Table 2), as well as means and standard deviations for these $\mathrm{CH}-\mathrm{S}$ and PAI subscales (Table 3) was conducted.

Independent variables generating significant Pearson correlation coefficients were then entered into a stepwise multiple regression to predict the degree of unique contribution each variable has for predicting supervisor ratings of job performance. The resulting regression model explained a significant amount of the variance in the value of supervisor ratings of correctional officer job performance, and produced $\mathrm{R}^{2}=.31, \mathrm{R}^{2}$ Adjusted $=.28, \mathrm{~F}(4,92)=10.20$, $p=.000$. In regard to variables retained in the model $\mathrm{CH}-\mathrm{S}$ Critical Factors appeared to provide the greatest contribution to the prediction model followed by $\mathrm{CH}-\mathrm{S}$ IMS, PAI ARD-Obsessive-Compulsive (ARD-O), and PAI BOR-Self-Harm (BOR-S), respectively (Table 4).

Table 1. Pearson Correlation Coefficients Between Supervisor Ratings of Job Performance and $\mathrm{CH}-\mathrm{S}$ and PAI Subscales

\begin{tabular}{|c|c|c|c|c|}
\hline & Variable & $\begin{array}{c}\text { Supervisor } \\
\text { Ratings }\end{array}$ & Variable & $\begin{array}{c}\text { Supervisor } \\
\text { Ratings }\end{array}$ \\
\hline \multirow{4}{*}{$\mathrm{CH}-\mathrm{S}$} & & & AI (Conti.) & \\
\hline & IMS & $-.24 *$ & PAR-Hypervigilance & .01 \\
\hline & Critical Items & $-.33 * *$ & PAR-Persecution & $-.21 *$ \\
\hline & Critical Factors & $-.40 * * *$ & PAR-Resentment & $-.23 *$ \\
\hline \multirow[t]{16}{*}{ PAI } & & & SCZ-Psychotic Experiences & -.05 \\
\hline & SOM-Conversion & -.01 & SCZ-Social Detachment & -.17 \\
\hline & SOM-Somatization & -.01 & SCZ-Thought Disorder & -.03 \\
\hline & SOM-Health Concerns & -.06 & BOR-Affective Instability & -.07 \\
\hline & ANX-Cognitive & .05 & BOR-Identity Problems & -.06 \\
\hline & ANX-Affective & .01 & BOR-Negative Relations & .00 \\
\hline & ANX-Physiological & -.05 & BOR-Self-Harm & $-.28 * *$ \\
\hline & ARD-Obsessive-Compulsive & $.25^{*}$ & ANT-Antisocial Behaviors & -.17 \\
\hline & ARD-Phobias & .00 & ANT-Egocentricity & $-.25 *$ \\
\hline & ARD-Traumatic Stress & -.05 & ANT-Stimulus-Seeking & -.19 \\
\hline & DEP-Cognitive & -.16 & AGG-Aggressive Attitude & $-.21 *$ \\
\hline & DEP-Affective & -.19 & AGG-Verbal Aggression & -.12 \\
\hline & DEP-Physiological & -.02 & AGG-Physical Aggression & -.04 \\
\hline & MAN-Activity Level & -.03 & Alcohol Problems & -.05 \\
\hline & MAN-Grandiosity & -.16 & Drug Problems & -.09 \\
\hline & MAN-Irritability & -.07 & & \\
\hline
\end{tabular}

$* p<.05 . * * p<.01 . * * * p<.000$. 
Table 2. Inter-scale Correlation Matrix Between Selected CH-S Scales and PAI Subscales

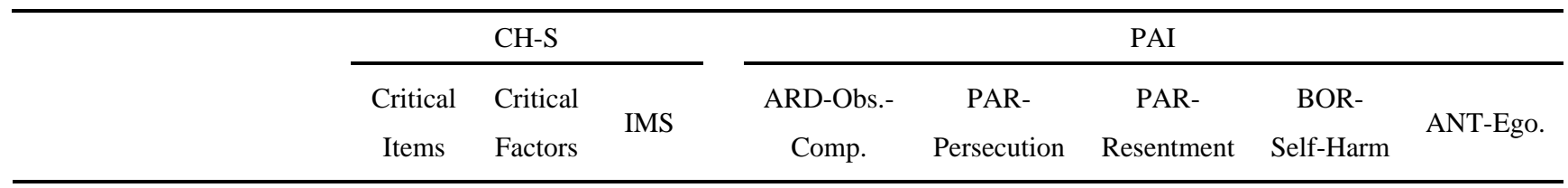

CH-S Critical Items

\begin{tabular}{|c|c|c|c|c|c|c|c|c|}
\hline CH-S Critical Factors & $.77 * *$ & & & & & & & \\
\hline CH-S IMS & 0.01 & 0.05 & & & & & & \\
\hline PAI ARD-Obs.-Comp. & 0.04 & -0.02 & 0 & & & & & \\
\hline PAI PAR-Persecution & $.25^{*}$ & $.20^{*}$ & -0.13 & 0.09 & & & & \\
\hline PAI PAR-Resentment & $.35^{* *}$ & $.38 * * *$ & -0.02 & 0.05 & $.50 * * *$ & & & \\
\hline PAI BOR-Self-Harm & $.37 * * *$ & $.27 * *$ & -0.12 & -0.02 & $.33 * *$ & $.33^{* *}$ & & \\
\hline PAI ANT-Ego. & $.44 * * *$ & $.33^{* *}$ & -0.04 & 0.15 & $.32 * *$ & $.23 *$ & $.34 * *$ & \\
\hline PAI AGG-Agg. Attitude & $.41 * * *$ & $.37 * * *$ & -0.13 & 0.05 & $.49 * * *$ & $.36 * * *$ & $.49 * * *$ & $.40 * * *$ \\
\hline
\end{tabular}

$* p<.05 . * * p<.01 . * * * p<.000$.

Table 3. Means and Standard Deviations for Selected CH-S Scales and PAI Subscales

\begin{tabular}{lcc}
\hline \multicolumn{1}{c}{ Independent Variables } & $M$ & $S D$ \\
\hline CH-S Critical Items & .40 & .92 \\
CH-S Critical Factors & .20 & .53 \\
CH-S IMS & 6.71 & 1.19 \\
PAI ARD-Obsessive-Compulsive & 49.19 & 7.97 \\
PAI PAR-Persecution & 44.47 & 5.03 \\
PAI PAR-Resentment & 43.04 & 7.09 \\
PAI BOR-Self-Harm & 43.87 & 5.73 \\
PAI ANT-Egocentricity & 45.10 & 5.89 \\
PAI AGG-Aggressive Attitude & 39.18 & 5.44 \\
\hline
\end{tabular}

Note: Means and standard deviations for the $\mathrm{CH}-\mathrm{S}$ stem from raw scale scores and $\mathrm{T}$ scores for the PAI.

Table 4. Stepwise Regression Analysis for Selected CH-S and PAI Subscales

\begin{tabular}{|c|c|c|c|c|c|}
\hline Variables & $B$ & $S E B$ & $\beta$ & $t$ & $p$ \\
\hline \multicolumn{6}{|l|}{$\mathrm{CH}-\mathrm{S}$} \\
\hline CHS IMS & -.34 & .12 & -.25 & -2.84 & .006 \\
\hline CHS CFs & -.51 & .14 & -.33 & -3.60 & .001 \\
\hline \multicolumn{6}{|l|}{ PAI } \\
\hline ARD-Obsessive-Compulsive & .03 & .01 & .24 & 2.75 & .007 \\
\hline BOR-Self-Harm & -.03 & .01 & -.21 & -2.35 & .021 \\
\hline
\end{tabular}

Sensitivity, specificity, positive predictive values (PPV), negative predictive values (NPV), and relative risk ratios were then calculated for the $\mathrm{CH}-\mathrm{S}$ scales using cut scores recommended by Tatman (2019b). Using a cut score of 2 Critical Factors revealed a 
sensitivity rate of $20 \%$, specificity rate of $98.78 \%$, PPV of $75 \%$, NPV of $87.10 \%$, and a global accuracy rate of $86.6 \%$ for predicting poor job performance in this sample. The difference between the sensitivity rate and PPV found here is noteworthy. Sensitivity is a metric of the test itself, and provides information about the probability that a test result will be positive (i.e., 2 or more Critical Factors) when the event (i.e., poor job performance ratings) is present. PPV, on the other hand, is a measurement of the population and provides the probability that poor performance would be identified if the applicant produces 2 or more Critical Factors. In other words, PPV answers the question "What is the chance this applicant will be rated by supervisors as having poor job performance if they generate 2 or more Critical Factors?", while sensitivity answers the question "What is the CH-S's ability, using a cut score of 2 or more Critical Factors, to identify poor job performance?" Therefore, based on these results it appears that when using a cut score of 2 Critical Factors the $\mathrm{CH}-\mathrm{S}$ detects poor job performance approximately $20 \%$ of the time (i.e., sensitivity). However, if a person has 2 or more Critical Factors there is a 75\% likelihood that they would be identified as being a poor performer (i.e., PPV). Risk ratios were also conducted using 2 Critical Factors and revealed a risk ratio score of $5.81(p<.0001)$. This suggests that individuals who generate 2 or more Critical Factors are almost 6 times more likely to be rated by supervises as exhibiting poor job performance compared to employees generating zero or one Critical Factors. Regarding the CH-S IMS, a cut score of 4 or less points revealed a sensitivity rate of $33.33 \%$, specificity rate of $96.34 \%$, PPV of $62.5 \%$, NPV of $88.76 \%$ and a global accuracy rate of $86.6 \%$ for predicting poor job performance in this sample. Risk ratio scores of 5.56 ( $p$ $<.0001)$ were also obtained using this IMS cut score.

Given that there were no known PAI subscale cut scores associated with correctional officer applicants, comparative analyses were then conducted using sensitivity, specificity, PPVs, NPVs, and global accuracy rates using cut scores of $1.5 S D$ and $2 S D$ from the mean $\mathrm{T}$ subscale score obtained in this study (Table 3). Results from these comparative analyses revealed that the $2 S D$ option showed marked improvement in terms of PPV, sensitivity and overall accuracy compared to the 1.5 SD option. Therefore, due to the direction of their respective Pearson correlation coefficients (Table 1), sensitivity, specificity, PPV, NPV and relative risk ratios were calculated using a cut score of $2 S D$ below the sample mean for ARD-O and $2 S D$ above the sample mean for BOR-S. Analyses for the ARD-O revealed that when using a cut of score of T score equal to or greater than 33 generated a sensitivity rate of $13.33 \%$, specificity rate of $97.56 \%$, PPV of $50.00 \%$, NPV of $86.02 \%$, and a global accuracy rate of $84.54 \%$ for predicting poor job performance in this sample. A risk ratio score of 3.58 ( $p=.023$ ) was also obtained using this two standard deviation below the ARD-O mean cut score. Analyses for the BOR-S revealed that when using a cut of score of T score at or greater than 56 generated a sensitivity rate of $26.67 \%$, specificity rate of $97.67 \%$, PPV of $66.67 \%$, and a global accuracy rate of $90.72 \%$ for predicting poor job performance in this sample. A risk ratio score of $5.76(p<.0001)$ was also obtained using this two standard deviation above the BOR-S mean cut score.

\section{Discussion}

Findings presented in this study support this study's first hypothesis that " $\mathrm{CH}-\mathrm{S}$ and PAI 
scores would significantly correlate with supervisor ratings of job performance." All three $\mathrm{CH}-\mathrm{S}$ scales showed significant correlations with job performance ratings, fully supporting this hypothesis. However, only 6 out of 33 PAI subscales analyzed showed significant linear relationships with job performance. This finding was particularly surprising given the widespread use of the PAI with law enforcement and correctional officers (Roberts et al., 1999; Weiss, 2010; Weiss \& Weiss, 2010). The remaining three hypotheses proposed in this study were supported. Results showed that $\mathrm{CH}-\mathrm{S}$ and PAI scores predicted job performance ratings (hypothesis 2), that the $\mathrm{CH}-\mathrm{S}$ provided the strongest contribution to the prediction of job performance ratings (hypothesis 3 ), and that the PAI provided subscales that contributed incremental validity to $\mathrm{CH}-\mathrm{S}$ scores in the prediction of supervisor ratings of correctional officer job performance (hypothesis 4). In addition to the surprising finding that only 6 of the 33 PAI subscales correlated with job performance ratings, it was particularly interesting to find that only 2 PAI subscales were retained in the prediction model. This result my stem from the significant inter-scale correlations observed between PAI subscales entered into the model (Table 2).

Findings presented in this study contribute to existing literature on pre-employment integrity and psychological testing. Specifically, the present findings presented in this study support existing literature (Tatman, 2019b) by showing that the $\mathrm{CH}-\mathrm{S}$ significantly predicted supervisor ratings of correctional officer job performance. Although it was surprising to see that $\mathrm{CH}-\mathrm{S}$ Critical Items did not significantly contribute to the prediction model, this result likely stemmed from the significant inter-scale correlation between $\mathrm{CH}-\mathrm{S}$ Critical Items and $\mathrm{CH}-\mathrm{S}$ Critical Factors ( $r=.77$; Table 2). Therefore, although $\mathrm{CH}-\mathrm{S}$ Critical Items was not included in the final prediction model, its strong correlation with job performance ratings $(r=$ -.33; Table 1) would suggest that $\mathrm{CH}-\mathrm{S}$ Critical Items would still provide meaningful information to hiring agencies regarding an applicant's risk for future counterproductive work behaviors and poor job performance. This study also provides new information to the existing literature on the $\mathrm{CH}-\mathrm{S}$ by identifying that the $\mathrm{CH}-\mathrm{S}$ provided the greatest contribution to a prediction model of job performance for correctional officers when combined with PAI subscale scores. Although this is a new finding for the $\mathrm{CH}-\mathrm{S}$, specifically, this finding is consistent with the literature on integrity tests, in general, which has found that integrity test results provide one of the strongest contributions and incremental validity to the prediction of job performance (Schmidt \& Hunter, 1998). Results from this study also provide new and noteworthy information to the field of personnel selection and assessment by identifying that the Personality Assessment Inventory (PAI) provided incremental validity above and beyond the $\mathrm{CH}-\mathrm{S}$ when predicting supervisor ratings of correctional officer job performance. Although the PAI Law Enforcement, Corrections, and Public Safety Selection Report (Roberts et al., 1999) has norms specific to correctional applicants, and has been widely used in pre-employment psychological evaluations for correctional officer applicants, research could not be found on its criterion validity when used for this purpose. Results obtained from this study provide the field with initial data that some PAI subscales are significantly correlated with supervisor ratings of correctional officer job performance, and provide incremental validity to this prediction above and beyond integrity test data. First, the strongest PAI subscale that contributed to the model was ARD-O, which assesses for 
intrusive thoughts or behaviors, rigidity, hyper attentiveness to details, perfectionism, and other characteristics of obsessive-compulsive disorder. The positive relationship found in this study would suggest that as supervisor ratings decreased traits associated with ARD-O also decreased. This is an interesting finding in that interpretations have only been provided for ARD-O sub-clinical elevations ( $T=55$ to 65 ) and clinically significant elevations ( $T$ at or greater than 65; Morey, 2003). No interpretation guidance has been given for low ARD-O scale scores. Based on the ARD-O item content, however, one could conclude that individuals scoring low on ARD-O may tend to be unorganized, hasty in their decision making, and have limited concern with details, which are linked, through this study, with poor job performance ratings. The positive association between BOR-S and supervisor ratings is also noteworthy. BOR-S measures an individual's tendency to act impulsively and without consideration of the consequences of their actions. Individuals scoring high in this subscale are at a heightened risk for impulsive behaviors that likely have a high potential for negative consequences, and which may be self-damaging or self-destructive (Morey). The sample of correctional officers used in this study generated BOR-S T scores $(M=43.87, S D$ $=5.73$; Table 3 ) that fell well below the $\mathrm{T}$ cut score recommended as being clinically relevant ( $\mathrm{T}$ at or great than 65; Morey). This finding suggests that subclinical scores on BOR-S may be relevant for identifying traits of impulsivity during pre-employment evaluations.

Readers should note that, although the present findings add to the existing literature, these remain initial findings. Additional research is recommended before generalizations should be made from these initial findings. The sample used in this study consisted of correctional officers in Iowa. Although this was the intended sample for this study, the relationship between the CH-S and PAI with correctional officer applicants from more urban and racial diverse settings would be a valuable compliment and comparison to the present study.

\section{References}

Berry, C. M., Sackett, P. R., \& Wiemann, S. (2007). A review of recent developments in integrity test research. Personnel Psychology, 60(2), 271-301. https://doi.org/10.1111/j.1744-6570.2007.00074.x

DeCoster-Martin, E., Weiss, W. U., Davis, R. D., \& Rostow, C. D. (2004). Compulsive traits and police officer performance. Journal of Police and Criminal Psychology, 19(2), 64-71. https://doi.org/10.1007/BF02813874

Fine, S. (2013). A look at cross-cultural integrity testing in three banks. Personnel Review, 42(3), 266-280. https://doi.org/10.1108/00483481311320408

Fine, S., Horowitz, I., Weigler, H., \& Basis, L. (2010). Is good character good enough? The effects of situational variables on the relationship between integrity and counterproductive work behaviors. Human Resource Management Review, 20(1), 73-84. https://doi.org/10.1016/j.hrmr.2009.03.010

Herrmann, D. S., \& Bedwell, S. (2014). Selecting and hiring psychologically fit probation officers: A focused examination of the PEPQ/PSR Plus. International Journal of Court Administration, 6(1), 1-9. https://doi.org/10.18352/ijca.117 
Jones, J. W., Cunningham, M. R., \& Dages, K. D. (2010). Pre-offer police integrity testing: Scientific foundations and professional issues. In P. A. Weiss (Ed.), Personality Assessment in Police Psychology: A $21^{\text {st }}$ Century Perspective (pp. 159-187). Springfield, IL: Charles C Thomas Publisher.

Lowmaster, S. E., \& Morey, L. C. (2012). Predicting law enforcement officer job performance with the Personality Assessment Inventory. Journal of Personality Assessment, 94(3), 254-261. https://doi.org/10.1080/00223891.2011.648295

Marcus, B., Ashton, M. C., \& Lee, K. (2013). A note on the incremental validity of integrity tests beyond standard personality inventories for the criterion of counterproductive behaviour. Canadian Journal of Administrative Sciences, 30(1), 18-25. https://doi.org/10.1002/cjas.1235

Morey, L. C. (2003). In A. S. Kaufman \& N. L. Kaufman (Eds.), Essentials of the PAI Assessment. Hoboken, NJ: John Wiley \& Sons, Inc.

Morey, L. C. (2007). The Personality Assessment Inventory professional manual (2 ${ }^{\text {nd }}$ ed.) Odessa, FL: Psychological Assessment Resources.

Nicol, A. M., \& Paunonen, S. V. (2002). Overt honesty measures predicting admissions: An index of validity or reliability. Psychological Reports, 90(1), 105-115. https://doi.org/10.2466/pr0.2002.90.1.105

Ones, D. S., Viswesvaran, C., \& Schmidt, F. (1993). Comprehensive meta-analysis of integrity test validities: Findings and implications for personnel selection and theories of job performance. Journal of Applied Psychology Monograph, 78(4), 679-703. https://doi.org/10.1037/0021-9010.78.4.679

Ones, D. S., Viswesvaran, C., \& Schmidt, F. L. (2003). Personality and absenteeism: A meta-analysis of integrity tests. European Journal of Personality, 17(SPEC. 1), S19-S38. https://doi.org/10.1002/per.487

Roberts, M., Thompson, J., \& Johnson, M. (1999). PAI Law Enforcement, Corrections, and Public Safety Selection Report module. Odessa, FL: Psychological Assessment Resources.

Roscoe, T., Duffee, D. E., Rivera, C., \& Smith, T. R. (2007). Arming probation officers: Correlates of the decision to arm at the departmental level 1. Criminal Justice Studies, 20(1), 43-63. https://doi.org/10.1080/14786010701241333

Sackett, P. R., \& Lievens, F. (2008). Personnel selection. Annual Review of Psychology, 59, 419-450. https://doi.org/10.1146/annurev.psych.59.103006.093716

Schmidt, F. L., \& Hunter, J. E. (1998). The validity and utility of selection methods in personnel psychology: Practical and theoretical implications of 85 years of research findings. Psychological Bulletin, 124(2), 262-274. https://doi.org/10.1037/0033-2909.124.2.262

Schmidt, F. L., Oh, I-S., Shaffer, J. A. (2016). The Validity and Utility of Selection Methods in Personnel Psychology: Practical and Theoretical Implications of 100 Years of Research Findings.

Retrieved

from 
https://www.testingtalent.net/wp-content/uploads/2017/04/2016-100-Yrs-Working-Paper-onSelection-Methods-Schmit-Mar-17.pdf

Shusman, E. J., \& Inwald, R. E. (1991). A longitudinal validation study of correctional officer job performance as predicted by the IPI and MMPI. Journal of Criminal Justice, 19(2), 173-180. https://doi.org/10.1016/0047-2352(91)90051-V

Small, S., \& Torres, S. (2001). Arming probation officers: Enhancing public confidence and officer safety. Federal Probation, 65(3), 24-28.

Tatman, A. W. (2019a). Critical Hire Assessments: Technical Manual for the Critical Hire-Screen and Critical Hire-Personality Assessment. Urbandale, Iowa: Critical Hire, PLC.

Tatman, A. W. (2019b). Predicting Correctional Officer Employment Success: Criterion Validity for the Critical Hire - Screen. Manuscript submitted for publication.

Tatman, A. W., \& Huss, M. T. (2019a). Criminal thinking and pre-employment integrity testing: Correlations between the Texas Christian University Criminal Thinking Scales and Critical Hire-Screen. Journal of Human Resource Management, 22(1), 65-69.

Tatman, A. W., \& Huss, M. T. (2019b). Initial reliability and validity for the Critical Hire Screen. Personnel Assessment and Decisions. In press.

Tatman, A. W., Kreamer, S., \& Dix, M. (2014). Employee Screening and Selection in Community Corrections: A Comprehensive Process. Perspectives, 38(4), 116-126.

Wanek, J. E. (1999). Integrity and honesty testing: What do we know? How do we use it? International Journal of Selection \& Assessment, 7(4), 183-195. https://doi.org/10.1111/1468-2389.00118

Weiss, P. A. (2010). Use of the PAI in personnel selection. In M. A. Blais, M.R. Baity, \& C. J. Hopwood (Eds.), Clinical applications of the Personality Assessment Inventory (pp. 163-176). New York, NY, US: Routledge/Tayler \& Francis Group.

Weiss, P. A., Hitchcock, J. H., Weiss, W. U., Rostow, C., \& Davis, R. (2008). The Personality Assessment Inventory borderline, drug, and alcohol scales as predictors of overall performance in police officers: A series of exploratory analyses. Policing and Society, 18, 301-310. https://doi.org/10.1080/10439460802091708

Weiss, W. U., Rostow, C., Davis, R., \& Decoster-Martin, E. (2004). The Personality Assessment Inventory as a selection device for law enforcement personnel. Journal of Police and Criminal Psychology, 19(2), 23-29. https://doi.org/10.1007/BF02813870

Weiss, W. U., \& Weiss, P. A. (2010). Use of the Personality Assessment Inventory in police and security personnel selection. In P. A. Weiss (Ed.), Personality assessment in police psychology: A $21^{\text {st }}$ century perspective (pp. 72-90). Springfield, IL, US: Charles Thomas.

Weiss, W. U., Zehner, S. N., Davis, R. D., Rostow, C., \& Decoster-Martin, E. (2005). Problematic police performance and the Personality Assessment Inventory. Journal of Police and Criminal Psychology, 20(1), 16-21. https://doi.org/10.1007/BF02806703 


\section{Copyright Disclaimer}

Copyright for this article is retained by the author(s), with first publication rights granted to the journal.

This is an open-access article distributed under the terms and conditions of the Creative Commons Attribution license (http://creativecommons.org/licenses/by/4.0/). 